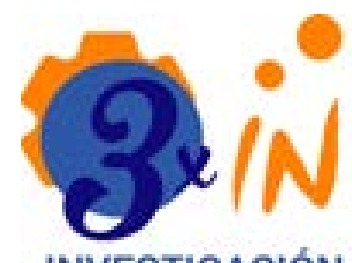

INVESTIGACIÓN E INNOVACION en INGENERIAS ISSN2344-9452.

Open Access:

Recibido:

15 agosto de 2017

Aceptado:

4 diciembre de 2017

Correspondencia:

ecabrera7@hotmail.com

DOI

10.17081/invinno.6.2.3110

(c) $\mathrm{O}$

Copyright: Cabrera et al

\section{Aprovechamiento de la fruta del árbol de pan (Artocarpus Altilis) para la obtención de un derivado alimenticio (harina)}

\author{
Use of the fruit of the bread tree (Artocarpus \\ altilis) to obtain a food derivative (flour)
}

\author{
Eduardo Cabrera Durán, Janinna Melissa Castillo Martinez, \\ Universidad del Magdalena, Colombia
}

\section{Resumen}

Objetivo: Aprovechar la fruta del Árbol de Pan (Artocarpus altilis) para obtener harina alimenticia.

Metodología: Se seleccionó la fruta por tamaño y grados de madurez (indicados por las medidas de Grados ${ }^{\circ}$ Brix). De esta manera se controlaron fenómenos de empardeamiento enzimático durante las etapas de pelado y de las actividades anteriores al secado, el cual fue desarrollado en un horno de acero inoxidable a una temperatura entre $50^{\circ} \mathrm{C}$ y $65^{\circ} \mathrm{C}$.

Resultados: La molienda fue llevada a cabo en un molino industrial de martillo. Además, se establecieron características físico-químicas de la fruta en cada uno de los grados de maduración resultantes, así como los análisis bromatológico parcial, microbiológico y sensorial.

Conclusión: Después de comparar las propiedades alimenticias de la harina de fruto de pan con las harinas de otras especies vegetales, se recomienda este proceso como una alternativa creativa innovadora para la formulación y elaboración de alimentos idóneos, es decir, procesados para proporcionar elementos proteicos, acompañados de calorías no vacías.

Palabras clave: Fruta de pan, harina, rendimiento porcentual.

Abstract

Objective: To take advantage of the fruit of the Tree of Bread (Artocarpus altilis), to obtain nutritional flour.

Methodology: The fruit was selected by size and degrees of maturity (indicated by the Grade ${ }^{\circ}$ Brix measurements), controlling in this way phenomena of enzymatic patching (empardeamiento) during the peeling stages and of the activities prior to drying, which was developed in an oven stainless steel at a temperature between $50^{\circ} \mathrm{C}$ and $65^{\circ} \mathrm{C}$.

Results: Grinding was carried out in an industrial hammer mill. In addition, physical-chemical characteristics were established in the fruit in each of the resulting degrees of maturity. As well as the bromatological partial, microbiological and sensorial analyzes.

Conclusion: After comparing the nutritional properties of breadfruit flour with the flours of other vegetable species, this process is indicated as an innovative creative alternative on the use and exploitation of many vegetable species for the formulation and elaboration of suitable processed foods. to provide protein elements, accompanied by non-empty calories.

Keywords: Fruit of bread, flour, percentage yield.

Como citar este articulo (IEEE) E. Cabrera - Durán, y

J. Castillo - Martinez, "Aprovechamiento de la fruta del árbol de pan (Artocarpus Altilis) para la obtención de un derivado alimenticio (harina)", Revista Investigación e Innovación en Ingenierias, vol. 6, n. 2, 2018. DOI: 10.17081/ invinno.6.2.3110 


\section{Introducción}

La harina es el producto resultante de la deshidratación de un fruto y su posterior molienda. El proceso de transformación más común de la fruta para obtener harina comprende las etapas de recepción, almacenamiento, selección, lavado, pelado, rodajeado y aplicación de ácido ascórbico para la reducción del pardeamiento enzimático. Luego se realiza el secado, molienda y empaque [1].

El árbol de pan es una especie cultivada en cultivos de "pan coger" por moradores de los municipios de Ciénaga, la Zona Bananera y los barrios de Gaira y Mamatoco en el departamento del Magdalena. No obstante, dado el potencial alimenticio que posee, podría ser aprovechada de una mejor forma. Como alimento humano, es, en efecto, de gran utilidad debido a su alto contenido de carbohidratos (20 a 35\%), calcio, hierro, fósforo y vitaminas C. Además, se destaca por su importancia en la protección de aguas y suelos.

La fruta del árbol de pan (Artocarpus altilis) posee un alto valor alimenticio: su contenido proteico $(8.80 \mathrm{~g} / 100 \mathrm{~g})$ es mayor que el de la papa $(1.90 \mathrm{~g} / 100 \mathrm{~g})$, la yuca $(0.80 \mathrm{~g} / 100 \mathrm{~g})$, el maíz $(7.60 \mathrm{~g} / 100 \mathrm{~g})$, el plátano $(1.20 \mathrm{~g} / 100 \mathrm{~g})$ y el arroz $(7.80 \mathrm{~g} / 100 \mathrm{~g})$. Además es rico en niacina, calcio, potasio y hierro

Ahora bien, la fabricación de harina de alta calidad a partir de frutas requiere contar con materia prima de buena calidad y un especial cuidado a los factores que influyen en el proceso de secado y molienda [2-3].

El estado de madurez de las frutas es importante para obtener un producto con las características deseadas, de modo que la cosecha de estas debe efectuarse en el momento preciso. La recolección en una época indebida favorece el desarrollo de condiciones perjudiciales para la elaboración y conservación del producto.

Una recolección temprana impide, por ejemplo, la maduración del producto durante el almacenamiento. Aparte de que la fruta demasiado verde es propensa a alteraciones fisiológicas y a una elevada transpiración.

Por otro lado, el producto cosechado tardíamente posee un tiempo de conservación menor, y es más sensible a la podredumbre y a los efectos adversos de la manipulación.

\section{Deshidratación}

La deshidratación es una operación unitaria de acabado que se aplica a los diferentes tipos de alimentos, en especial a frutas y hortalizas, fundamentándose en la remoción y extracción de cantidades apropiadas de humedad y/o agua libre, en forma de vapor. Esta solo se efectúa si la presión parcial de vapor en agua en el medio que rodea en producto que se desea secar es inferior a la presión de vapor en la superficie del cuerpo húmedo [4].

\section{Principios inherentes a la deshidratación de los alimentos}

Los factores determinantes para acondicionar el aire utilizado en el secado de un producto, cuyo contenido de humedad es uniforme en todas sus 
partes, son: Velocidad, presión, humedad y temperatura. Estos se ndican en la curva típica de secado (Figura 1).

La curva de secado artificial comprende: un periodo preliminar de secado, indicado en la figura por la porción "A-A"; también comprende un primer período de intensidad de secado constante o periodo "A-B", un primer período de intensidad de secado decreciente o porción "B-C", y un segundo período de intensidad de secado decreciente o periodo de velocidad decreciente de secado de segunda fase, indicado por la porción "C-D".

En el periodo "A-A", la condición del aire de secado y superficie humedad de la muestra se encuentran en equilibrio hasta el límite ascendente. En el período "A-B", la cantidad de agua evaporada corresponde a una determinada unidad de tiempo. Además, la parte superficial del alimento está completamente húmeda y la evaporación depende solo del estado del aire respecto a factores como su velocidad, temperatura y contenido de humedad [5] .

Figura 1. Curva característica de secado artificial

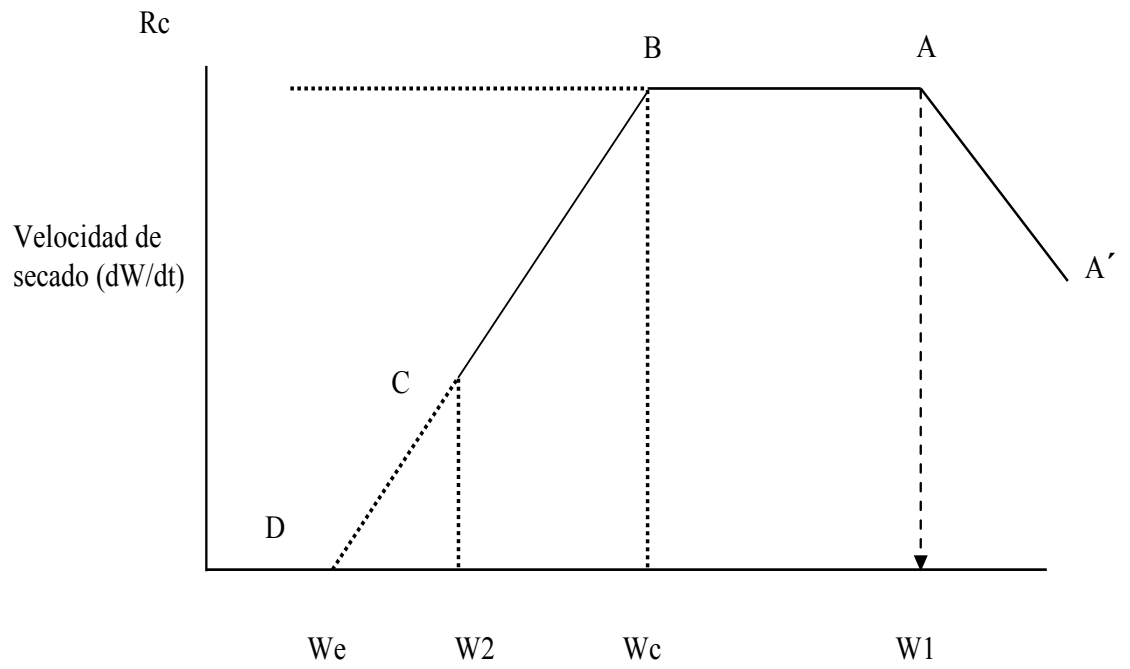

Cabe anotar que si las condiciones del aire permanecen constantes, la velocidad de secado también permanecerá constante. Puede suponerse que el aire forma tres capas separadas: una capa estacionaria muy fina que se halla en contacto con la superficie del alimento saturada de vapor de agua. Por encima de esta capa se encuentra otra que se mueve lentamente, pero con mayor rapidez en sus zonas más extensas con las cuales se une a las corrientes principales de aire caliente, transportando de esta forma el vapor de agua de la capa estacionaria [5].

El vapor de agua produce un descenso en la temperatura del producto (Temperatura Estacionaria), fenómeno que se denomina "Enfriamiento Evaporativo". En este momento, el calor que se aporta al producto con el aire compensa totalmente la pérdida de calor por enfriamiento evaporativo. Esta temperatura estacionaria, que es inferior a la temperatura del aire, es la misma que indica el termómetro del bulbo húmedo cuando se expone a las mismas condiciones que el producto. 
La diferencia entre las temperaturas de los termómetros del bulbo húmedo y bulbo seco colocados en una corriente de aire se denomina "Depresión de Bulbo Húmedo".

En el primer período B-C, el contenido de humedad libre en el punto B se denomina Contenido de Humedad Critica (WC). Este período corresponde a la parte del ciclo de secado en el que la totalidad de la superficie no está ya completamente mojada y $\vee$ disminuye continuamente hasta que al final de este periodo se seca. Por consiguiente, a medida que la superficie mojada disminuye, la velocidad también. El segundo periodo C-D se presenta justamente cuando la superficie está completamente seca.

El calor necesario para la evaporación se transmite desde el aire a la superficie seca del producto, y desde ella a través del sólido hasta la zona de evaporación; luego el agua se evapora en el interior de producto y el vapor se mueve a través de él hacia el seno de la corriente de aire.

Hacia el punto B, la temperatura del alimento que se deseca corresponde a la de bulbo húmedo del aire circulante. Posteriormente, la temperatura del alimento ocurre por efecto de la temperatura del aire (temperatura del bulbo seco).

Esta temperatura estacionaria, que es inferior a la temperatura del aire, es la misma que indica el termómetro del bulbo húmedo cuando se expone a las mismas condiciones presentes en el producto.

\section{Fruta de árbol de pan (Artocarpus altilis)}

El árbol de pan (Artocarpus altilis y similares) es una especie perteneciente al género de los Artocarpus, en la tribu de las Artocarpeae, de la familia de las Moraceae, con cientos de variedades de árboles distribuidas desde el sudeste asiático hasta la Polinesia, pasando por Oceanía. Entre la variedad de especies se encuentran: Artocarpus blancoi, Artocarpus camansi, Artocarpus communis, Artocarpus incisa, Artocarpus mariannensis, Artocarpus rima y Artocarpus heterophyllus. Esta ultima junto con la Artocarpus altilis son las especies más cultivadas del género en todo el mundo [6].

El fruto desarrollado está compuesto por la unión de muchos ovarios (es sincárpico) y difiere según la especie de Artocarpus. Generalmente es redondo, ovalado $u$ oblongo y mide entre 9 y $20 \mathrm{~cm}$ de ancho y más de $30 \mathrm{~cm}$ de largo, como un melón. Puede pesar entre $250 \mathrm{~g}$ y $6 \mathrm{~kg}$. La piel consta de entre 5 y 7 capas, cada una de las cuales pertenece a una flor individual. La textura es suave y carnosa. Su color oscila entre el verde claro, el verde amarillento y el amarillo. Igualmente, la piel está cubierta de pequeñas espinas. La carne es de color amarillo oscuro, con una pulpa fibrosa y cremosa, con un $60 \%$ de almidón y más proteínas que el plátano o el ñame. Puede presentar muchas simientes (que también son comestibles) o puede no tenerlas. En este último caso, el fruto se desarrolla por partenocarpia.

Los frutos d el árbol, como ya se ha dicho, son muy alimenticios, ya que aparte de su valor proteico, son ricos en carbohidratos y contienen una buena fuente de vitaminas y minerales. 
Tabla 1. Composición bromatológica de la fruta del árbol de pan (Artocarpus altilis)

\begin{tabular}{|l|c|c|}
\hline \multirow{2}{*}{ Alimento } & \multicolumn{2}{|c|}{ Parte de la Fruta } \\
\hline Humedad $(\mathrm{g} / 100 \mathrm{~g})$ & $35.1-56.8$ & $62.7-89.2$ \\
\hline Proteínas $(\mathrm{g} / 100 \mathrm{~g})$ & $5.25-13.3$ & $1.3-2.24$ \\
\hline Grasas $(\mathrm{g} / 100 \mathrm{~g})$ & $2.59-5.59$ & $0.1-0.86$ \\
\hline Cenizas $(\mathrm{g} / 100 \mathrm{~g})$ & $1.5-5.58$ & $0.56-1.2$ \\
\hline Carbohidratos $(\mathrm{g} / 100 \mathrm{~g})$ & $30.8-44.0$ & $21.5-29.5$ \\
\hline Fibra $(\mathrm{g} / 100 \mathrm{~g})$ & $1.34-2.14$ & $1.08-2.1$ \\
\hline Calorías $(\mathrm{kcal} / 100 \mathrm{~g})$ & --- & $105-109$ \\
\hline Calcio $(\mathrm{mg} / 100 \mathrm{~g})$ & 0.1 & 0.05 \\
\hline Tiamina $(\mathrm{mg} / 100 \mathrm{~g})$ & 0.25 & $0.08-0.09$ \\
\hline Riboflavina $(\mathrm{mg} / 100 \mathrm{~g})$ & 0.10 & $0.03-0.07$ \\
\hline Niacina $(\mathrm{mg} / 100 \mathrm{~g})$ & 3.54 & $0.51-0.92$ \\
\hline Acido ascórbico $(\mathrm{mg} / 100 \mathrm{~g})$ & 13.7 & 15.33 \\
\hline
\end{tabular}

En su madurez fisiológica, la fruta de pan (Artocarpus altilis) presenta un color verde oscuro y los segmentos de la cáscara se tornan más redondeados y lisos que en las frutas inmaduras. En la cáscara de frutas listas para cosechar se pueden encontrar manchas de látex. El amarillamiento de la piel indica que el proceso de maduración ha comenzado [6].

Las frutas de buena calidad presentan un color verde oscuro, firme, con pedúnculo intacto y libre de defectos (como cicatrices, mancha de sol, rajaduras, golpes y daño de insecto) y podredumbres.

La uniformidad de forma, tamaño y peso también son factores de calidad muy importantes. La pulpa de fruta de pan (porción comestible) contiene entre $25-30 \mathrm{~g} / 100 \mathrm{~g}$ ) (peso fresco) de carbohidratos, siendo la mitad almidón.

Algunas enfermedades del fruto se manifiestan usualmente después de daños mecánicos o de daño por frío, en tanto que las pudriciones pueden ser causadas por Phytophthora palmivora, Rhizopus artocarpi o Botryobasidium salmonicola.

El árbol del pan tiene dos cultivariedades: en una, el fruto tiene semillas; y en la otra, carece de ellas y solo se compone de una masa suave y blancuzca[3].

Las semillas tiene aguijones, su peso promedio es de 1.3 kilogramos, su ta- 
maño de 17 x 15.5 centímetros y un número promedio de 64 semillas.

Tabla 2. Distribución porcentual en peso del las partes compuestas de la fruta del árbol de pan (Artocarpus altilis) con semilla.

\begin{tabular}{|c|c|c|}
\hline Partes de la Fruta & Peso & Composición(Porcentaje) \\
\hline \multirow[t]{2}{*}{$\begin{array}{l}\text { Carne } \\
\text { (Pulpa) }\end{array}$} & \multirow[t]{2}{*}{ 1,3 kilogramos. } & $42 \%$ es semilla (546 gramos). \\
\hline & & $\begin{array}{l}58 \% \text { es fibra, cáscara leñosa y } \\
\text { cutícula apergaminada. }\end{array}$ \\
\hline \multirow[t]{2}{*}{ Semilla } & \multirow[t]{2}{*}{8.5 gramos } & $\begin{array}{l}80 \% \text { es nuez comestible. } \\
20 \% \text { es cáscara leñosa y cutícula }\end{array}$ \\
\hline & & apergaminada \\
\hline
\end{tabular}

Como ya se informó, el árbol de pan (Artocarpus altilis) sin semillas (inseminífero) tiene un peso pro medio por fruto de 1.5 kilogramos, y presenta algunas variaciones: el tipo Barbacoas en Nariño (Colombia), por ejemplo, es redondo, liso, y su tamaño es de $18 \times 16.5$ centímetros. En Jamaica y en Providencia (Colombia), es redondo, liso y mide 16 centímetros de diámetro. En San Andrés (Colombia), es ovoide aguijoneado, y puede medir hasta 21 × 17 centímetros.

En el árbol de pan sin semillas, la hoja tiene de 7 a 11 lóbulos, los cuales llegan casi hasta el nervio medio. En la parte basal de la copa, las hojas miden $63 x$ 45 centímetros y en la parte superior de la misma, alcanzan 47 x 36 centímetros en promedio. El árbol de pan sin semillas se propaga principalmente por esqueje de raíz y por injerto sobre patrón de frutopán con semillas.

Tabla 3. Composición del árbol de pan (Artocarpus altilis) sin semilla

\begin{tabular}{|l|c|c|}
\hline Fruta Completa $\quad(\mathrm{Kg})$ & Parte de la Fruta & $\begin{array}{c}\text { Composición (Porcentaje) } \\
(\mathrm{Kg} / 100 \mathrm{Kg})\end{array}$ \\
\hline \multirow{2}{*}{1.50} & Pulpa aprovechable & 70 \\
\cline { 2 - 3 } & Corteza y corazón & 30 \\
\hline
\end{tabular}




\section{Materiales y método}

La presente investigación se realizo en las instalaciones de la Planta Piloto de procesamiento Pesquero de la Universidad del Magdalena, ubicada en el corregimiento de Taganga, distrito de Santa Marta (Colombia).

Se analizaron y describieron cada una de las técnicas utilizadas en el proceso de obtención de harina a partir del árbol de pan (Artocarpus altilis) a través de la recopilación bibliográfica existente y la observación directa del tema, en forma experimental, con el fin de comprobar la validez o no de la hipótesis de trabajo.

El procedimiento consistió en seleccionar varias muestras representativas de la fruta y aplicarles las operaciones indicadas en el diagrama de flujo descrito en la Figura 2.

Figura 2. Diagrama de flujo de la producción de harina a partir del fruto del árbol de pan (Artocarpus altilis)

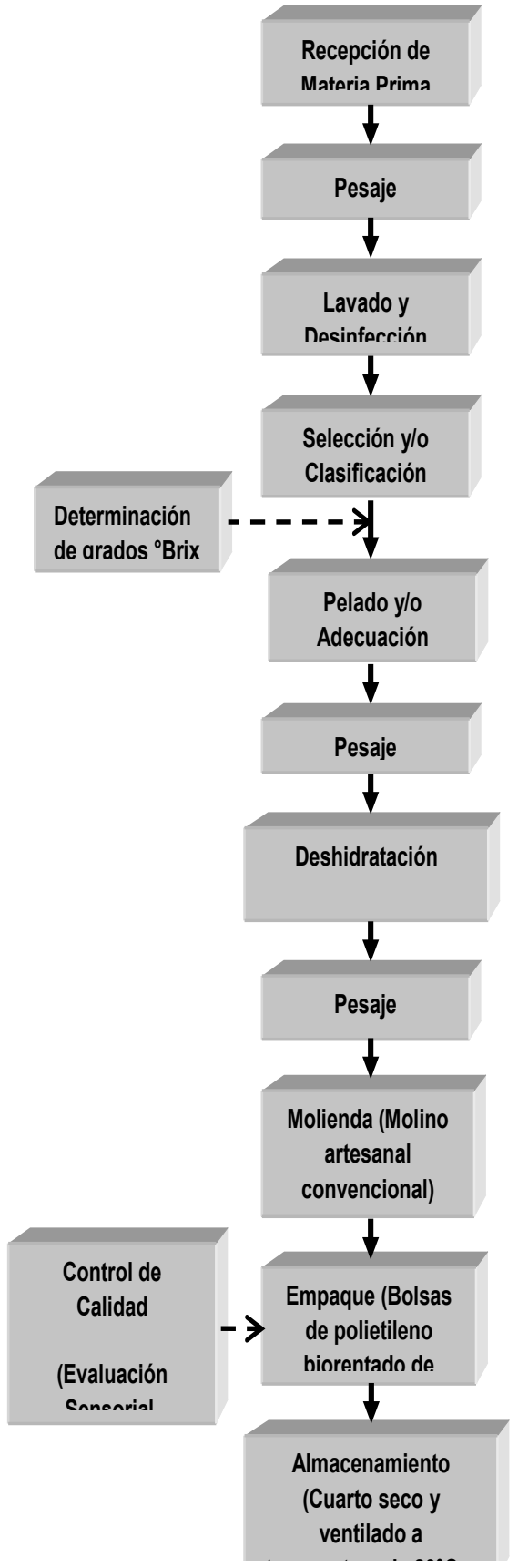


Además, se efectuaron pruebas de laboratorio con el fin de establecer los grados Brix (*), que indican el porcentaje de acidez presente en cada uno de los grados de maduración de la fruta. Por otra parte, en el proceso para la obtención de la harina se aplicaron los principios básicos de HACCP para identificar, valorar y controlar factores críticos que pudieran afectar el producto final; además, se realizaron los respectivos análisis bromatológicos, microbiológicos y sensoriales necesarios para garantizar que la harina sea óptima para el consumo humano.

Finalmente, se determinaron los equipos indispensables para la elaboración del producto y se estimaron los costos directos e indirectos necesarios para la producción de la harina de la fruta del árbol de pan (Artocarpus altilis).

\section{Resultados}

Producción de harina a partir de la fruta de árbol de pan (artocarpus altilis).

Equipos y procedimiento general

Para la producción de la harina, fueron necesarios equipos que se utilizaron durante las etapas del proceso y en la realización de análisis indispensables para garantizar la idoneidad de la harina y sus productos derivados para el consumo humano.

Entre los equipos utilizados se encuentran: balanza de humedad, potenciometro, refractómetro, deshidratador, horno mufla.

Adquisición y recepción de materia prima

Los frutos del árbol de pan (Artocarpus altilis) fueron adquiridos en el municipio de Ciénaga, departamento del Magdalena-Colombia.

Pesaje

Los frutos enteros fueron pesados en una balanza analítica de precisión, con el fin de determinar el rendimiento del proceso.

Lavado y desinfección

el lavado se realizó con agua clorada (2 ppm), buscando reducir la carga bacteriana y eliminar impurezas y suciedades.

\section{Selección y clasificación}

Para garantizar la calidad del producto final se aceptó la fruta que no presentara magulladuras, golpes, rajaduras, hongos, laceraciones, picaduras de insectos, aves o mordeduras de roedores y que tuviera un peso no inferior a 696 gramos.

\section{Pesaje}

Se determinó el peso promedio de la muestras y se garantizó que las frutas cumplieran con los parámetros de selección establecidos para obtener el rendimiento del producto final. 
Peso promedio de Muestreo 1 de la fruta del árbol de pan (Artocarpus altilis).

Peso promedio de Muestreo 2 de la fruta del árbol de pan (Artocarpus altilis).

Peso promedio de Muestreo 3 de la fruta del árbol de pan (Artocarpus altilis)

$1007,7 \mathrm{~g}$

Pelado o adecuación

La cáscara se retiró manualmente, evitando que quedara pedazos adherido a la fruta, para no proporcionar a la harina sabor amargo.

Pesaje

Las tajadas finas del fruto del árbol de pan (Artocarpus altilis)

fueron pesadas igual que los desechos, cáscaras y semillas.

Tabla 4. Valores de los pesos de la fruta y los componentes como la cáscara, la semilla, sus desechos y el peso de la pulpa resultante

\begin{tabular}{|c|c|c|c|c|}
\hline Muestra & $\begin{array}{c}\text { Peso total } \\
\text { Cascara (g) }\end{array}$ & $\begin{array}{c}\text { Peso total } \\
\text { Desecho (g) }\end{array}$ & $\begin{array}{c}\text { Peso total } \\
\text { Semilla(g) }\end{array}$ & $\begin{array}{c}\text { Peso total } \\
\text { Pulpa(g) }\end{array}$ \\
\hline 51 & 10.735 & 3.688 & 4.155 & 33.040 \\
\hline
\end{tabular}

\section{Deshidratación}

Una vez se trocearon las frutas fueron llevadas al horno deshidratador marca Montero y, posteriormente, se determinó su nuevo peso.

Molienda

Para este menester, se empleó un molino convencional alimentado con las tajadas del fruto de pan deshidratadas para obtener harina.

\section{Empaque}

El empaque fue realizado en bolsas de polietileno biorentado, y se selló de manera hermética en unidades de 250 gramos. Se tomaron muestras de la harina para realizar los análisis bromatológicos y microbiológicos.

\section{Almacenamiento}

La harina se almacenó en un lugar seco y fresco, a una temperatura de $28^{\circ} \mathrm{C}$ y $69 \%$ de humedad relativa en promedio; también se protegió de la acción de insectos, roedores y de la luz solar y artificial.

Rendimiento porcentual de la harina producida a partir del número total de frutas del árbol de pan (Artocarpus altilis)

Para determinar el rendimiento total, se compararon los pesos de las harinas producidas en los distintos muestreos y los pesos iniciales de 
las 51 frutas del árbol de pan (Artocarpus altilis). El rendimiento total fue de $17,9 \%$, rendimiento que se considera alto respecto al rendimiento de las harinas de otras especies vegetales, que alcanzan un rendimiento aproximado del $8 \%$.

Peso inicial de las 51 frutas del árbol de pan $=51.618,0 \mathrm{~g}$

Peso total de la harina $=9.232,7 \mathrm{~g}$

Analisis realizados a la fruta de árbol de pan

(Artocarpus altilis)

Grado de madurez de la fruta del árbol de pan

(Artocarpus altilis)

Se establecieron seis grados de color de acuerdo con la evolución de la maduración y las necesidades del mercado y de los consumidores.

Tabla 5. Estados de maduracion de la fruta de árbol de pan (Articarpus altilis)

\begin{tabular}{|l|l|}
\hline Grado de Maduración & \multicolumn{1}{|c|}{ Caracteristicas } \\
\hline Grado 1. Verde lima & $\begin{array}{l}\text { Color normal de la fruta fresca. Ideal para el } \\
\text { procesamiento de subproductos (harina y chips). }\end{array}$ \\
\hline Grado 2. Ligeramente verde & $\begin{array}{l}\text { Primer cambio de color durante el ciclo de maduración. } \\
\text { Adecuada para el procesamiento de subproductos } \\
\text { (harina y chips) }\end{array}$ \\
\hline Grado 3. Verde amarillo & $\begin{array}{l}\text { Recomendado para la distribución al detallista durante } \\
\text { la estación fría. Apropiada para el procesamiento de } \\
\text { subproductos (harina y chips). }\end{array}$ \\
\hline Grado 5. Amarillo & $\begin{array}{l}\text { Pronunciado estado inicial del ciclo de maduración. } \\
\text { Listo para entregar al detallista durante la } \\
\text { estación caliente. }\end{array}$ \\
\hline Grado 6. Amarillo con pintas cafés. & $\begin{array}{l}\text { Ideal para el consumo y procesamiento de } \\
\text { subproductos (bocadillos, mermelada, jugos) } \\
\text { Color amarillo con un alto valor nutritivo y } \\
\text { maduración. }\end{array}$ \\
\hline
\end{tabular}


Figura 3. Fruto Pan (Artocarpus altilis)

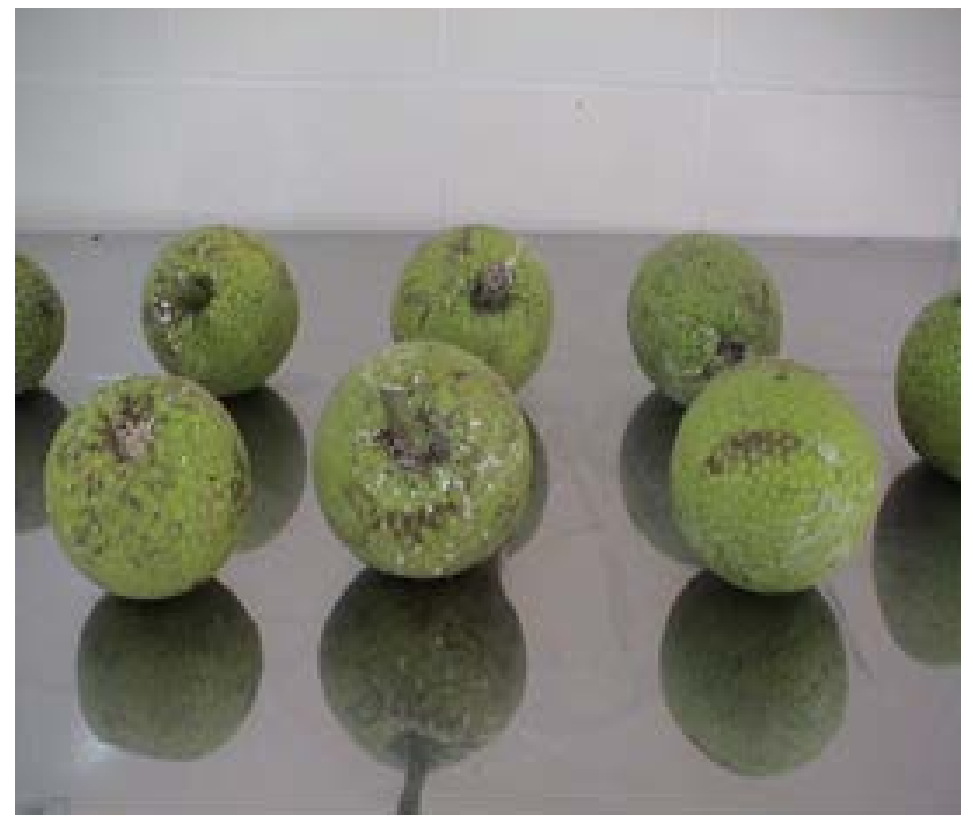

Cambios en el contenido de sólidos solubles totales BRIX(\%)

De acuerdo con las pruebas realizadas, se estableció el contenido de sólidos solubles (Brix (\%)) en cada uno de los estados de maduración de la fruta del árbol de pan (Artocarpus altilis) (Tabla 7).

Tabla 6. . Porcentaje de sólidos solubles totales Brix(\%) presentes en cada uno de los grados de madurez de la fruta del árbol de pan (Artocarpus altilis)

\begin{tabular}{|l|l|l|l|l|l|l|}
\hline Estado de Maduración & 1 & 2 & 3 & 4 & 5 & 6 \\
\hline BRIX(\%) & 65 & 67 & 72 & 75 & 79 & 83 \\
\hline
\end{tabular}

\section{Cambio de Acidez}

Se encontró que la acidez de la pulpa, expresada en función del pH, alcanzó el máximo climatérico un poco después y acuosa. A medida que la maduración progresaba ocurrió un ligero descenso: la piel o cáscara de la fruta mostró una tendencia similar, pero ligeramente retardada con respecto a la de la pulpa. Ello demuestra que la maduración ocurre de la masa hacia la cáscara. 
Tabla 7. Porcentaje de acidez expresada en pH presente en cada uno de los grados de madurez de la fruta del árbol de pan (Artocarpus altilis)

\begin{tabular}{|l|cc|}
\hline Estado de Maduración & $\mathrm{pH}$ & Acidez \\
\hline 1 - Verde lima & 7.2 & 0.51 \\
\hline 2 - Ligeramente verde & 6.88 & 0.55 \\
\hline 3 - Verde amarillo & 6.68 & 0.65 \\
\hline 4 - Ligeramente amarillo & 6.42 & 0.69 \\
\hline 5 - Amarillo & 6.22 & 0.67 \\
\hline 6 - Amarillo con puntas cafés & 5.95 & 0.63 \\
\hline
\end{tabular}

Análisis realizados a la harina producida a partir de la fruta de árbol de pan (Artocarpus altilis)

Examen microscópico

Los granos de harina de la fruta del árbol de pan (Artocarpus altilis) fueron analizados al microscopio, observándose que no había materiales extraños ni contaminación por insectos.

Análisis bromatológico

Además, se realizó el análisis bromatológico parcial a la harina resultante a fin de determinar los componentes alimenticios como: carbohidratos, fibra, proteína, cenizas y humedad (Tabla 9).

Tabla 8. Contenido bromatológico de la harina de la fruta de árbol de pan (Artocarpus altilis) sin semillas

\begin{tabular}{|l|c|}
\hline Análisis & Resultados de Base Húmeda \\
\hline Húmedad $(\mathrm{g} / 100 \mathrm{~g})$ & 11,48 \\
\hline Cenizas $(\mathrm{g} / 100 \mathrm{~g})$ & 3,01 \\
\hline Grasa $(\mathrm{g} / 100 \mathrm{~g})$ & 1,07 \\
\hline Proteina $(\mathrm{g} / 100 \mathrm{~g})$ & 6,20 \\
\hline Fibra $(\mathrm{g} / 100 \mathrm{~g})$ & 0,30 \\
\hline Carbohidratos $(\mathrm{g} / 100 \mathrm{~g})$ & 78,17 \\
\hline
\end{tabular}


Figura 4. Harina de Fruto Pan (Artocarpus altilis)

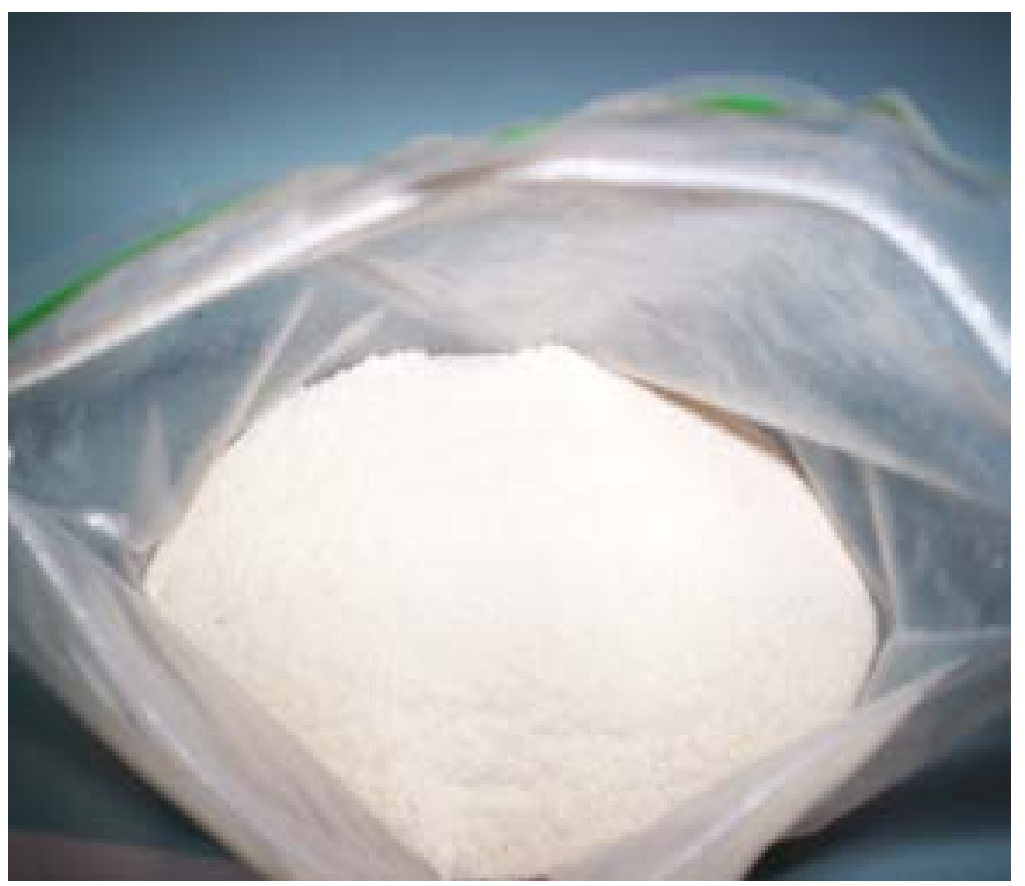

\section{Resultados microbiológicos}

Los resultados señalaron que el número más probable de coliformes totales en la muestra de la harina de la fruta del árbol de pan (Artocarpus altilis) fue $<10$ y el de coliformes fecales, igual a cero.

El recuento de mesofilos en la harina de la fruta del árbol de pan (Artocarpus altilis) fue $<10$. Asimismo, resultó negativa y la presencia de Staphylococcus coagulada positiva.

Tabla 9. Microorganismos patógenos presentes en la muestra de la harina de la fruta del árbol de pan (Artocarpus altilis)

\begin{tabular}{|l|c|}
\hline Microorganismo & Muestra de la Harina \\
\hline Recuento total de aerobios Mesofilos (UFC/g) & $<10$ \\
\hline Coniformes fecales (NMP/g) & $<10$ \\
\hline Recuento de hongos y levaduras (UFC/g) & $<10$ \\
\hline Recuento de Coliformes totales (NMP/g) & $(-)$ \\
\hline Staphylococcus coagulasa + (UFC/g) & \\
\hline
\end{tabular}




\section{Análisis sensorial}

Con relación al aroma, sabor y textura de los productos elaborados (empanada, arepa, deditos y buñuelo), los resultados estadísticos mostraron gran aceptación durante las pruebas de degustación.Se tabularon las apreciaciones hechas por 20 catadores con respecto a la aceptación de los productos: empanada, dedito, arepa y buñuelo.

Estos resultados fueron analizados con el Test de Cochran, el cual compara la aproximación del chi-cuadrado con la ecuación de distribución $Q$, estudiando solamente la información de las hileras que satisfacen la inecuación $0<T i<K$ y excluyendo aquellas hileras en que no haya diferencia $y$, por lo tanto, no satisfagan la citada inecuación.

Se asume que no hay diferencia en el tratamiento, es decir, todas las muestras son tratadas en igualdad de condiciones, por la hipótesis nula Ho, considerando el número de respuestas correctas.

$$
H o=E\left(T_{1}\right)=E\left(T_{2}\right)=E\left(T_{3}\right)=\ldots \ldots \ldots \ldots . .=E\left(T_{K}\right)
$$

Si no existe efecto en el tratamiento, el test de Cochran $Q$, con =K-1 grados de libertad se escribe como:

$$
Q=\frac{K(K-1) \sum_{K=1}^{K}\left(T_{K}-\bar{T}\right)^{2}}{\mathrm{~K} \sum_{\mathrm{i}=1}^{\mathrm{n}} \mathrm{Ti}-\left(\sum_{i=1}^{n}(T i)\right)^{2}}
$$

Al desarrollar el analisis, este indicó que no hubo diferencias estadísticas significativas en la evaluación por parte de los panelistas entre los olores, sabores y texturas de los productos alimenticios formulados y elaborados con la harina del fruto del árbol de pan (Artocarpus altilis).

Análisis de costos para la elaboración de la harina de la fruta del árbol de pan (artocarpus altilis) y de los cuatro productos alimenticios derivados

Costos preliminares para la elaboración de la harina de la fruta del árbol de pan (Artocarpus altilis) 
Tabla 10. Costos variables durante el proceso de la obtención de harina a partir del fruto pan (Artocarpus altilis)

\begin{tabular}{|l|c|c|c|}
\hline Concepto & $\begin{array}{c}\text { Unidad } \\
\text { (Kg) }\end{array}$ & $\begin{array}{c}\text { Costo por Unidad } \\
\text { (Pesos) }\end{array}$ & $\begin{array}{c}\text { Costo Total } \\
\text { (Pesos) }\end{array}$ \\
\hline Fruto Pan & 51.60 & 75 & 3.870 \\
\hline Agua & 5.0 & 30 & 150 \\
\hline Hipoclorito de Sodio & $30(\mathrm{cc})$ & 12 & 360 \\
Mano de Obra & 1 & 1.875 & $\mathbf{6 . 2 5 5}$ \\
\hline \multicolumn{2}{|c|}{ Total Costos Variables } & & \\
\hline
\end{tabular}

Tabla 11. Costos fijos durante el proceso de la obtención de harina a partir del fruto pan (Artocarpus altilis).

\begin{tabular}{|l|c|}
\hline $\begin{array}{l}\text { Concepto } \\
\text { (Pesos) }\end{array}$ & Costo Total \\
\hline Energía Eléctrica & 850 \\
\hline Gas & 670 \\
\hline Depreciación & 217 \\
\hline Total Costos Fijos & 1737 \\
\hline
\end{tabular}

Total de Costos Totales $=\mathrm{CV}+\mathrm{CF}$

$$
\begin{aligned}
& =6.255+1.737 \\
& =7.992
\end{aligned}
$$

Con base en la cantidad de harina de fruto pan obtenida, de los 51,6 kilogramos procesados se obtuvo un resultado de 9.61 kilogramo de harina. Por ende, el valor por kilogramo de la harina de fruto pan es de 831,6 pesos/kg. 


\section{Conclusiones}

La materia prima adquirida en el municipio de Ciénaga presentó apariencia, textura y sabor aceptables para el procesamiento en la harina.

El nivel de humedad de la harina de la fruta del árbol de pan (Artocarpus altilis) fue igual a 11,48g /100g.

El porcentaje de grasa $(1,07 \mathrm{~g} / 100 \mathrm{~g})$ en la harina de la fruta del árbol de pan (Artocarpus altilis) fue menor que el valor establecido en la harina fabricada con su semilla (6,0 g / $100 \mathrm{~g})$.

El fruto del árbol de pan (Artocarpus altilis) presenta mayor contenido de proteína $(6,02 \mathrm{~g} / 100 \mathrm{~g})$ que el referenciado para la papa, la yuca, el maíz, el plátano y el arroz; además, es rico en niacina, calcio, potasio y hierro.

El contenido de fibra encontrado para la harina de fruto del árbol de pan (Artocarpus altilis) fue igual a $0,30 \mathrm{~g} / 100 \mathrm{~g}$, carbohidratos totales $78,18 \mathrm{~g} / 100 \mathrm{~g}$ y el de cenizas, $3,01 \mathrm{~g} / 100 \mathrm{~g}$.

El estado de maduración 2 fue adecuado para la fabricación de harina, ya que así el fruto presentó textura firme y ligeramente pegajosa, favorable en suma para la manipulación de la fruta al momento de realizar la operación de pelado.

El rendimiento porcentual de la harina producida a partir del número total de frutas del árbol de pan (artocarpus altilis) fue de $17,9 \%$.

El recuento de mesofilos en la harina del fruto del árbol de pan fue < 10; y el de hongos y levaduras < 10. También se constató la presencia negativa de coniformes totales y coniformes fecales (NMP/g) en la harina.

El recuento de Staphylococcus coagulasa positiva presentó recuento negativo en todos los estados ensayados.

Con relación al aroma, sabor y textura de los productos elaborados (empanada, arepa, deditos y buñuelo) a partir de la harina del fruto de pan (Artocarpus altilis), los resultados estadísticos mostraron una gran aceptación durante las pruebas de degustación, al analizarse según la prueba no paramétrica de Cochran.

Por último, el costo preliminar de producción de harina del fruto del árbol de pan valor (Artocarpus altilis) fue de $\$ 831,6 / \mathrm{kg}$.

\section{Referencias bibliográficas}

1. L. Acero, Guía para el cultivo y aprovechamiento del "Árbol del pan" Artocarpus altilis. Convenio Andrés Bello, 1998.

2. E. Barriga Almenárez, Estudio de factibilidad para el montaje de una planta productora de harina de plátano en el departamento de Córdoba. Montería: Gobernación de Córdoba, 1996. 3. F. Beltrán, Análisis de factores de riesgo y determinación de puntos críticos de control en procesamiento de alimentos. Medellín: Universidad de Antioquia. Facultad Nacional de Salud Pública, Departamento de Formación Avanzada, 1988.

4. E. Juárez Hernández, Uso de la energía solar, en deshidratación de frutas y verduras. México: Universidad Autónoma de Puebla, 1998. 
5. A. Lacera, A. Castro García, E. Cabrera Durán, y L. Banderas Narvaez, Deshidratación de banano (Musa cavendish) mango (Manguífera Indica) y piña (Ananas comusus) para el consumo humano. Santa Marta, 1996, p. 125. Tesis de postgrado (Especialista en Ciencias y Tecnología de Alimentos). Universidad del Magdalena. Instituto de Formación Avanzada (IFA). Especialización en Ciencias y Tecnología de Alimentos.

6. A. Kader, Fruta de pan: recomendaciones para mantener la calidad postcosecha. Estados Unidos: Postharvest Technology Research \& Information Center, 2006. 